\title{
VISUALIZATION OF BOUNDARY LAYER SEPARATION AND PASSIVE FLOW CONTROL ON AIRFOILS AND BODIES IN WIND-TUNNEL AND IN-FLIGHT EXPERIMENTS
}

\author{
Lukas POPELKA, Jana KUKLOVA, David SIMURDA, Natalie SOUCKOVA, Milan MATEJKA, \\ Vaclav URUBA*
}

\begin{abstract}
Infrared camera, Particle Image Velocimetry, smoke-wire, tuft filaments and oil-flow visualization techniques were used for wind-tunnel and in-flight investigation of boundary layer separation, both stall and separation bubbles, related to the low-Reynolds numbers transition mechanism. Airfoils of Wortmann FX66 series and FX66 series wing-fuselage interaction, as well as modern airfoils and their wing-fuselage geometry were subject to study. The presence of previously identified structures in the CFD modelling, such as horse-shoe vortices, was confirmed in the flow.
\end{abstract}

Wind-tunnels and in-flight measurements on sailplanes were carried out and effect of passive flow control devices - vortex generators - was surveyed; namely counter-rotating vortex generators and Zig-zag type turbulators were applied. Separation suppression and consequent drag coefficient reduction of test aircrafts was reached. PIV investigation was further extended by Time-Resolved techniques.

An important study on structure of the turbulent flow in the lower atmosphere, creating an environment of the soaring flight, was presented.

\footnotetext{
- Lukas Popelka, Institute of Thermomechanics, Academy of Sciences of the Czech Republic, Dolejskova 5, Prague 8, Czech Republic, popelka@it.cas.cz

Jana Kuklova, Department of Applied Mathematics, CTU in Prague - Faculty of Transportation Sciences, Konviktska 20, Prague 1, Czech Republic, kuklojan@fd.cvut.cz

David Simurda, Institute of Thermomechanics, Academy of Sciences of the Czech Republic, Dolejskova 5, Prague 8, Czech Republic, simurda@it.cas.cz

Natalie Souckova, Institute of Thermomechanics, Academy of Sciences of the Czech Republic, Dolejskova 5, Prague 8, Czech Republic, natalies@it.cas.cz

Milan Matejka, Institute of Thermomechanics, Academy of Sciences of the Czech Republic, Dolejskova 5, Prague 8, Czech Republic, Milan.Matejka@fs.cvut.cz

Vaclav Uruba, Institute of Thermomechanics, Academy of Sciences of the Czech Republic, Dolejskova 5, Prague 8, Czech Republic, uruba@it.cas.cz
} 


\section{INTRODUCTION}

Flow visualization techniques often enable first insight into the investigated problem, their application is spreading from wind-tunnel laboratory conditions into real conditions, being used in-flight testing. Refined procedures also may provide valuable feedback while coupling the data of CFD analysis with experimental results.

The typical configuration of sailplane outer shape is fixed for many years and has been thoroughly investigated [1]. Still the combination of all available analysis methods can bring better understanding of flowfield and consequently in improvement in design process. Moreover, as the quest for performance lead to further extension of laminar flow and larger flap deflections, there are new phenomenas appearing, such as laminar and turbulent separation on control surfaces.

Passive flow control devices supply momentum to the boundary layer in the vicinity of sailplane surface; they can speed up transition process in order to prevent from laminar separation or suppress turbulent separation. Although the passive flow control devices often show detrimental performance effect in off-design condition, still their simple application and certain reliability in service make their usage worthwhile.

Boundary layer development on wing and empennage airfoils, wing with winglets and entire configuration was investigated. Gained knowledge has been used for improvement of experimental methodology. The results of drag reduction are directly transferrable to the sailplanes in service and also for new development.

\section{Geometries Subject to Study}

The primary and applied research was coupled with three Czech designed and manufactured sailplanes.

VSO10 is the most widely used single-seat sailplane in the Czech Republic. TST10 is a microlight sailplane with self-launching ability, aimed at club class handicapped competition. In order to extend the cases of Wortmann FX66 airfoil series and FX66 series wing-fuselage interaction, German $\mathrm{SH}$ Cirrus sailplane was used. For mutual comparison, the last generation club class sailplane, the HPH304C was added to the research programme, Figure 1.

VSO10 test programme employed an outer wing segment, adopted for wind-tunnel height. The whole section features linear transition from Wortmann FX60-126 to FX61163 airfoil [2]; considering the tip itself, dominant geometry is the FX60-126 with 25\% chord aileron. Enabling mutual comparison, the wingtip with aileron was built in the negative moulds of HPH304C sailplane. For wing-fuselage interaction study, a series sailplane VSO10C was used.

SH Cirrus sailplane wing is using a combination of published [2] Wortmann FX66-S-196 airfoil on its root and FX66-S-161 on its tip.

TST10 research programme was initiated by in-flight measurements on a particular selflaunching TST-10a. The fuselage shape followed published coordinates [3] (Model No. 1) and, together with a Wortmann FX66 series wing airfoil [2], created a suitable test case for this interaction investigation, denoted as T10. The geometry of the computational model was slightly simplified in comparison to the real aircraft. The 1:5 scale wind-tunnel model was based on the previously mentioned geometry for CFD. The span was reduced to fit the height of the test section. The fillets of the real geometry were retained. 


\section{AnALYSIS Methods}

Three CFD codes, three wind-tunnels and three test aircrafts were used for analysis of flow, with particular details on transition coupled with separation bubble and both laminar and turbulent separation.

\section{a. Numerical modelling}

For the airfoil analysis, standard tool Xfoil [4] was used. In order to investigate the properties of the whole wing, XFLR5 [5] software was employed.

Commercial code Fluent 6.3 was used for 3D numerical simulation of wing-fuselage interaction. Turbulent flow was modelled using realizable $k-\varepsilon$ model of turbulence, which performs well in flows involving rotation, boundary layers under strong adverse pressure gradients, separation and recirculation. Spalart-Allmaras and sst k- $\omega$ turbulence models were assessed as well. Near-wall flow was modelled using a combination of a two-layer model and wall functions.

Vortex identification procedures have enabled to study origin of the horse-shoe vortex and its propagation along interaction geometry.

\section{b. Wind-tunnel measurement}

The closed-circuit, open test section, $750 \times 550 \mathrm{~mm}^{2}$ cross-section, general purpose wind-tunnel of the Faculty of Mechanical Engineering, Czech Technical University in Prague was used for smoke-wire and oil flow visualization. Airfoil model with circular end plates was located horizontally. Typical Reynolds number was $\operatorname{Re}=3 \cdot 10^{5}$ and inlet turbulence intensity $\mathrm{Tu}=2.2 \%$.

Blow-down rig with outlet cross-section $250 \times 250 \mathrm{~mm}^{2}$ of the Institute of Thermomechanics Academy of Sciences CR, was employed for Time-Resolved PIV measurement at $\operatorname{Re}=10^{5}$ and $\mathrm{Tu}=0.5 \%$.

The closed-circuit, closed test section, research wind-tunnel of the Institute of Thermomechanics Academy of Sciences CR was used for all remaining test programme. A test section of dimensions $865 \times 485 \times 900 \mathrm{~mm}^{3}$ was designed for airfoil and wing-body investigations [6]. Circular end plates provide an attachment for both types of models. The turntables are $500 \mathrm{~mm}$ in diameter and are flush with the wind-tunnel walls. Typical Reynolds number was $\operatorname{Re}=5 \cdot 10^{5}$, inlet turbulence intensity Tu through whole range of velocities was $0.25 \%$.

\section{c. In-flight measurement}

Standard pressure instruments and GPS-based technologies were used for flight path control.

Oil flow visualisations at several positions along wingspan were performed on three sailplanes, VSO10, TST10a and SH Cirrus. Oil was applied on the surface prior to the take-off and a flight of 10 minutes duration was carried out. The airspeed was held constant during the whole flight, typically $V=100 \mathrm{~km} / \mathrm{h}$ IAS, even during the climb and approach to landing.

An array of tufts was applied to the wing root area of tested sailplanes. Video recordings by a cameras located on the tail-boom or on the fuselage top were acquired. To cover the common service range, airspeeds $\mathrm{V}$ ranging from 85 to $160 \mathrm{~km} / \mathrm{h}$ IAS were selected. An aim to investigate structure of the turbulent flow in lower atmosphere, the environment of the soaring flights, was pursued. Thermal convection, with updrafts (commonly used by circling) and sink areas (crossed by straight flight) was studied by a data acquisition system, carried by TST10a sailplane, Figure 2. Dantec MiniCTA system, USB cards NI6218, NI9211 and Omega pressure transducers were used. All probes, 
namely hot-wire or hot-film probes, standard total and static pressure tubes and a thermocouple, were located on a top of a pylon, located in front of a canopy, free from fuselage boundary layer and with only minor effect of its pressure field.

Acquired and thoroughly analysed data, Figure 3, show important features: a) all dataset follow $-5 / 3$ decay law, $b$ ) there is a full spectrum of frequencies, certainly ranging above $1 \mathrm{kHz}$, hence containing those capable to influence transition of boundary layer to turbulence, c) there is systematic difference of turbulence intensity in the thermals and in between of them, d) values of longitudinal component of turbulent velocity fluctuations intensity are of order $0.5 \%$.

Such results confirm earlier studies [7] and also indicate, that the closed circuit CAT $865 \times 485 \mathrm{~mm}^{2}$ and VAT $250 \times 250 \mathrm{~mm}^{2}$ wind-tunnels are adequate facilities for experiments aiming at direct comparison with in-flight conditions.

\section{AIRFOILS, EXTENSION TO WINGS}

\section{a. VSO10}

Xfoil and XFLR5 analysis revealed laminar separation on lower side of upward deflected aileron on VSO10 outer wing segment. This finding was confirmed by the testing in the $750 \times 550 \mathrm{~mm}^{2}$ wind-tunnel. CFD modelling of forced transition predicted wing roll rate improvement. Lift curve measurement confirmed improvement by Zig-zag type turbulator placed 0.03 x/c upstream aileron hinge, Figure 4 (lower branch of lift curves).

Beside that, turbulent separation take place on aileron upper surface, while positive flap deflections. Vane-type rectangular vortex generators of height $3 \mathrm{~mm}$, with their trailing edge located $0.07 \mathrm{x} / \mathrm{c}$ upstream aileron hinge, were used and substantial improvement of lift properties reached, Figure 4 (upper branch of lift curves).

Finally, a series of test flights was flown on VSO10C sailplane in order to establish influence of Zig-zag type turbulator $0.03 \mathrm{x} / \mathrm{c}$ upstream aileron hinge. Video recording of turn reversal from $-45 \mathrm{deg}$ to $+45 \mathrm{deg}$ bank angle at $\mathrm{V}=80 \mathrm{~km} / \mathrm{h}$ IAS. Measured mean time for such manoeuvres yielded $3.66 \mathrm{~s}$ for clean configuration and $3.50 \mathrm{~s}$ with turbulators installed. Considering the XFLR5 results, the improvement of roll-rate by passive flow control increases with decreasing airspeed. If we assume $V=5 \mathrm{~m} / \mathrm{s}$ as a critical part of initial take-off roll in aero-tow, the improvement is 2.4 times higher over $\mathrm{V}=80 \mathrm{~km} / \mathrm{h}$ IAS, hence sought improvement in aileron authority was gained.

\section{b. TST10}

Xfoil and XFLR5 analysis showed a potential of performance improvement on TST10 wing by turbulators on lower side. Smoke-wire visualization followed and separation bubble suppression was reached. An in-flight oil flow visualization was used for validation of separation onset and reattachment. Zig-zag turbulators were applied along wingspan. Speed-polar was measured and served as baseline for further analysis. Gained improvements are similar to successful case of Standard Cirrus sailplane [8] with $10.7 \%$ improvement of overall lift-to-drag ratio.

\section{c. SH Cirrus}

Local separation in the airfoil upper and lower surface boundary layer was studied, initially by Xfoil, Figure 5 and XFLR5 modelling. Surface flow visualization for optimum transition control was performed, Figure 6. An evidence of separation bubbles was found on entire wing, good agreement of turbulent reattachment location with CFD was found. As practical solution of passive flow control, both surfaces may be equipped by Zig-zag turbulators. 
FX66 family airfoils were further studied by Time-Resolved PIV system. Dantec TR PIV system, with Pegasus Laser $2 \times 10 \mathrm{~mJ}$ and NanoSense Mk. III camera, served for acquisition of 1635 double-images of $1280 \times 1024$ pixels resolution with frequency of $500 \mathrm{~Hz}$ in each test case - uncontrolled and controlled transition on FX66-S-196V1 airfoil. Although mean velocity fields, presented on Figure 7, namely for the separated boundary layer, correspond well to the established schemes, showing recirculation zone, no such flow behaviour is present in instantaneous data. There are sequences of isolated vortices driven downstream. Full potential of Time Resolved technique should be utilised for identifying the unsteady vortex structures.

\section{d. HPH304C}

Validation of infrared camera ThermaCAM P65 acquired temperature fields, varying in accordance with transport phenomena laws, was performed by comparison with standard oil-flow technique, Figure 8.

Previously mentioned effect of transition strips was studied, Figure 9, confirming separation bubble suppression. An important feature of accelerated laminar boundary layer, damping of the disturbances, was demonstrated on Figure 10. The HQ10 airfoil proved a high resistance to surface degradation, namely by roughness-due-to-insect.

\section{WING-FUSELAGE INTERACTION}

Since some of the effects taking place at the fuselage-wing junction [1] result in generation of vortex structures, these structures needed to be identified in the flowfield. Methods used in continued research were described in recent complex study [8].

\section{a. VSO10}

Lower gains of height in dolphin style use of thermals were onset for validation of proper function of wing-fuselage fairing of the VSO10 sailplane. Steep pull-outs from $V=140 \mathrm{~km} / \mathrm{h}$ IAS till stall were performed. During the whole manoeuvre the flow remained attached, as on Figure 11 . The separation revealed only approximately $5 \mathrm{~km} / \mathrm{h}$ above stall speed, with presence of buffeting, hence desirable properties were confirmed.

\section{b. TST10}

CFD analysis procedure and vortex identification was used for T10 test case geometry modelling [8]. Generation of the horse-shoe vortex was visualized, starting as a separated boundary layer on fuselage. Also, another much smaller counter-rotating vortex is observed closer to the leading edge. More or less they follow upper and bottom surface of the wing and stretch further downstream. Wind-tunnel visualizations, carried out for five angles of attack, confirmed the formation of a separation zone in the studied area, including the smaller inner vortex. Identical flow separation pattern was observed during in-flight tuft visualization.

\section{c. SH Cirrus}

Based on TST10 findings, an application of vortex generators was tested at airspeed $V=80 \mathrm{~km} / \mathrm{h}$. Except for short time periods of increased angle of attack by gusts, the triangular separated area was suppressed by application of a single vortex generator, Figure 12.

\section{Conclusions}

Synthesis of CFD, wind-tunnel and in-flight experiments was used for analysis of nominally $2 \mathrm{D}$ and $3 \mathrm{D}$ boundary layers on sailplane geometries. Better insight into the 
flow physics, mainly by visualizations, was gained and several cases of flow control studied.

Although the turbulators are standard devices, capable of speed up transition, vortex generators are rather sparsely used on sailplanes. Application of these passive flow control devices lead to improvement of both performance and handling of examined sailplanes.

\section{ACKNOWLEDGMENT}

The work has been supported by Ministry of Education, Youth and Sports of the Czech Republic within project No. 1M06031. Support by the Czech Science Foundation under grant No. GA 101/08/1112 is gratefully acknowledged.

Authors are indebted to their team colleagues, technicians and test pilots, namely Mr. Zdenek Kolek and Mr. Lubor Zeleny.

\section{REFERENCES}

[1] Thomas F.: Fundamentals of Sailplane Design, 3rd Ed., Maryland, USA, College Park Press, 1999, 274 p.

[2] Althaus D., Wortmann F.X.: Stuttgarter Profilkatalog I, 1st Ed., Braunschweig, Vieweg \& Sohn Verlagsgesellschaft, 1981, 320p.

[3] Boermans L.M.M., Terleth D.C.: Wind-tunnel Tests of Eight Sailplane Wing-Fuselage Combinations, Technical Soaring, Vol. 8, No. 3, 1984, pp. 70-85.

[4] Drela M., Youngren H.: Xfoil 6.9. MIT, 2001, 33 p., http://raphael.mit.edu/xfoil/

[5] Deperrois A.: Analysis of foils and wings operating at low Reynolds numbers. Guidelines for XFLR5 V4.15, 2009, 53 p.

[6] Popelka L.: Wind Tunnel Test Section for Airfoils and Bodies, Research Programme Feasibility Studies, Proceedings of the Conference Topical Problems of Fluid Mechanics 2008, Institute of Thermomechanics AS CR , Prague, 2008, pp. 85-88.

[7] Zanin B.Y.: Transition at Natural Conditions and Comparison with the Results of Wind Tunnel Studies. 2nd IUTAM Symposium on Laminar-Turbulent Transition. Novosibirsk, 1984. Springer-Verlag, Berlin, Heidelberg, 1985, pp.541-546.

[8] Popelka L., Zeleny L., Simurda D., Matejka M.: Wing-Body Interaction: Numerical simulation, Wind-tunnel and In-flight Testing, Technical Soaring, Vol. 34, No. 2, 2010, pp. 29-36. 

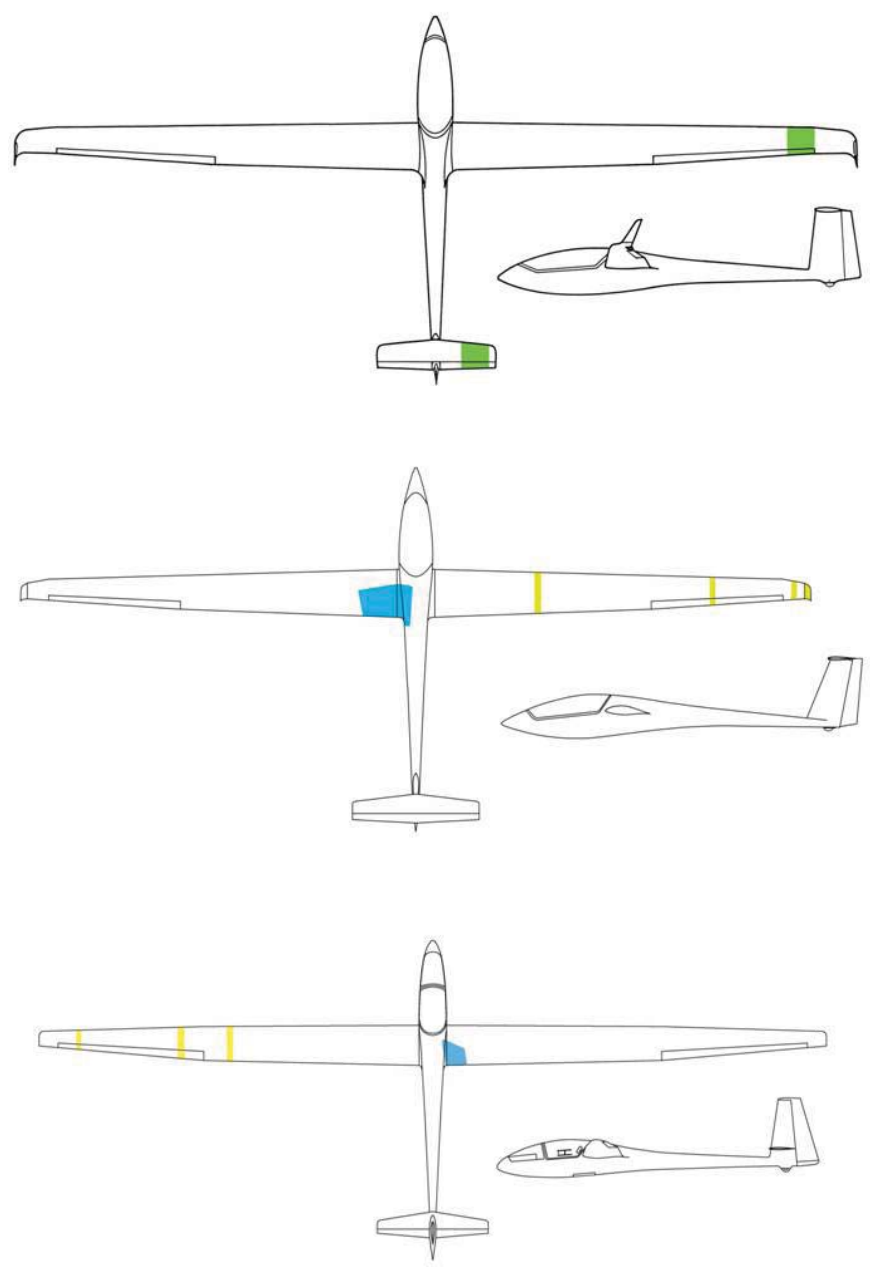

Figure 1: Club class sailplanes VSO10, HPH304C, both $15 \mathrm{~m}$ wingspan, SH Cirrus $(17.74 \mathrm{~m})$, self-launching sailplane TST10 $(15 \mathrm{~m})$ (from top to bottom). Full-scale wind-tunnel models (green), tuft array (blue), oil-flow pattern (yellow).

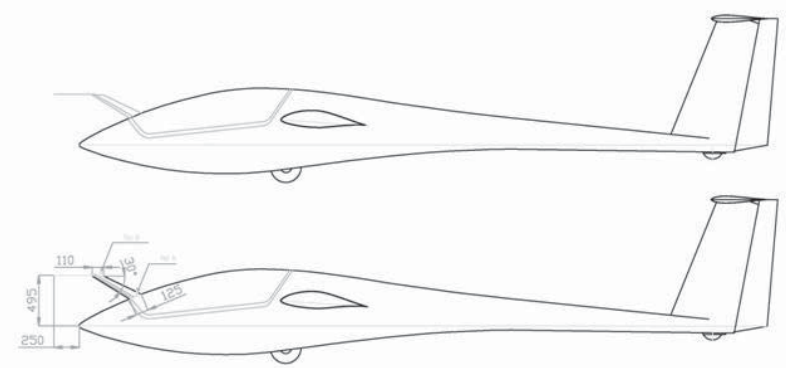

Figure 2: Fuselage drawing of the carrier sailplane TST10a, canopy attached pylon, holding CTA hot-wire and hot-film sensor, total and static pressure tubes and theromocouple. 

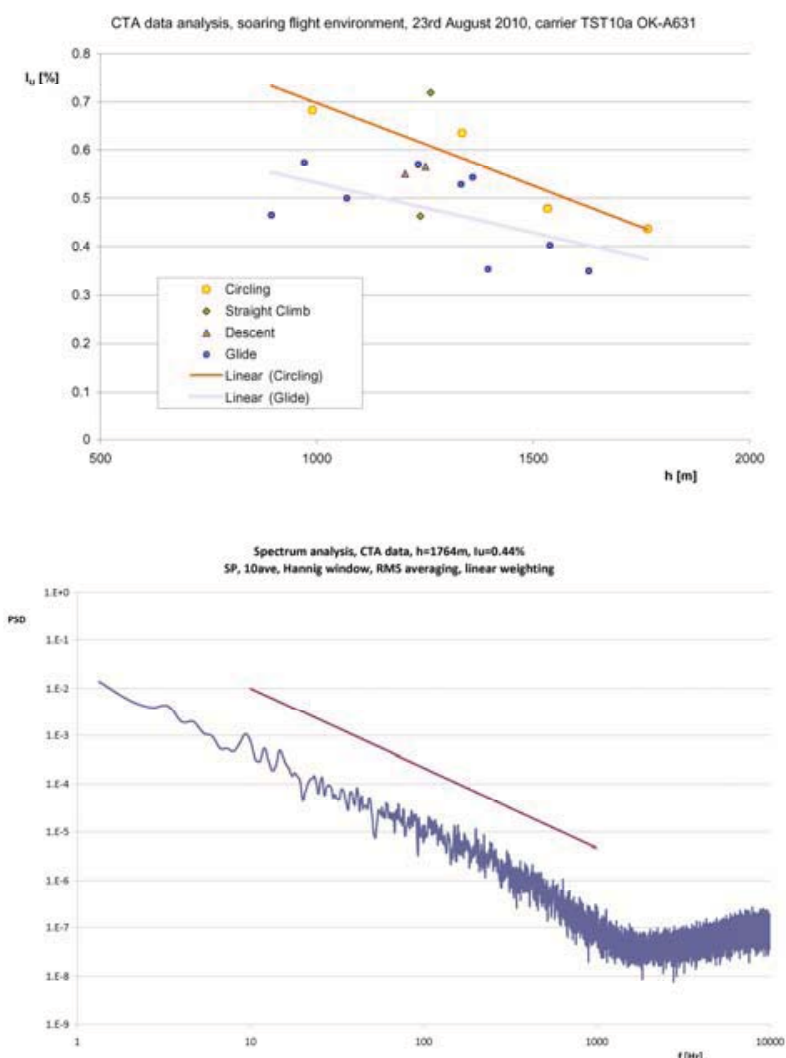

Figure 3: In-flight measurement of velocity turbulent fluctuations by CTA. Longitudinal velocity component turbulence intensity, as function of flight level and regime (top), spectrum analysis for one of the measurement dataset, comparison with $-5 / 3$ decay law (bottom).

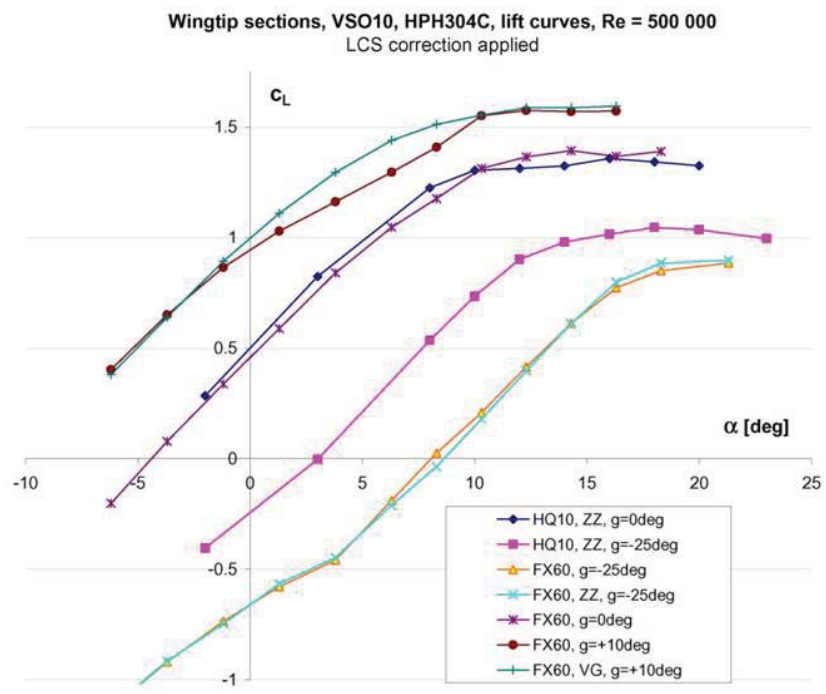

Figure 4: Comparison of lift curves, wind-tunnel measurement, $\operatorname{Re}=5 \cdot 10^{5}$, VSO10 and HPH304C wingtip sections, effect of passive flow control devices. Flap deflections $\gamma=-25,0,+10 d e g$. 


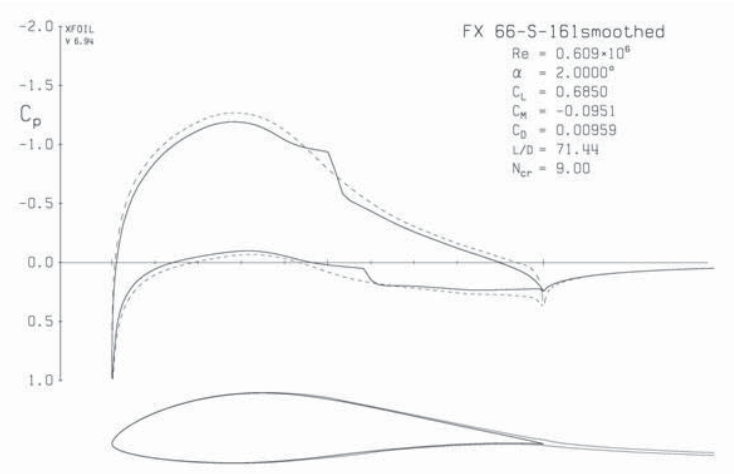

Figure 5: Xfoil analysis of SH Cirrus wingtip airfoil for airspeed of $100 \mathrm{~km} / \mathrm{h}$, viscous and inviscid pressure distribution, note the presence of the separation bubble.

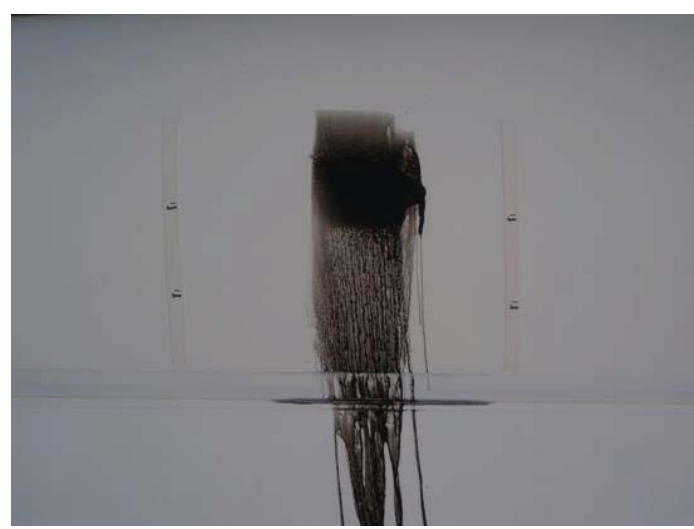

Figure 6: Oil-flow visualization on upper surface of outer wing segment of SH Cirrus sailplane, in the aileron region. Local chord $c=710 \mathrm{~mm}, \mathrm{~V}=100 \mathrm{~km} / \mathrm{h}$ IAS. Top to bottom: laminar boundary layer, separation bubble, turbulent boundary layer.
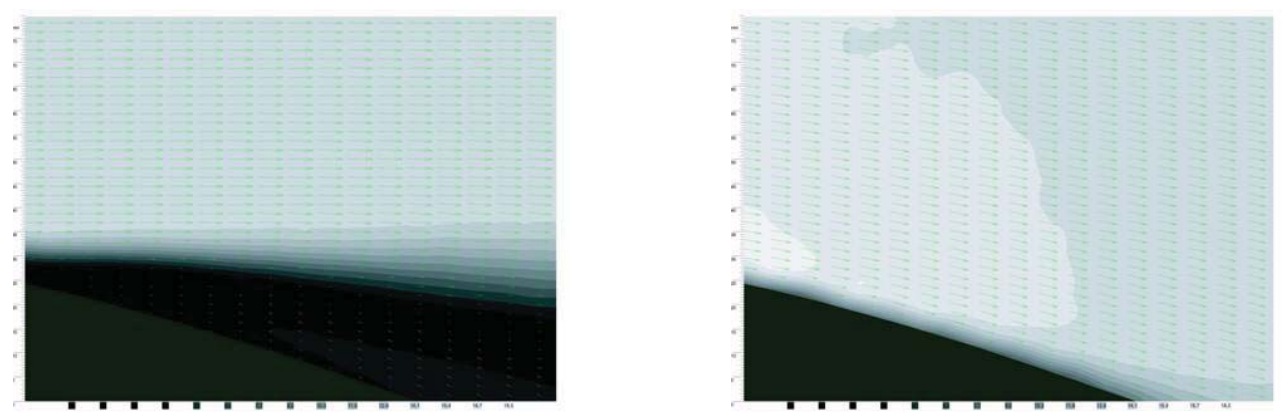

Figure 7 FX66-S-196V1 airfoil, TR PIV mean velocity field, top side, $R e=10^{5}$, uncontrolled case (left); passive-flow control: Zig-zag turbulator, $\mathrm{x}_{\mathrm{Tt}} / \mathrm{c}=0.1$ (right). 


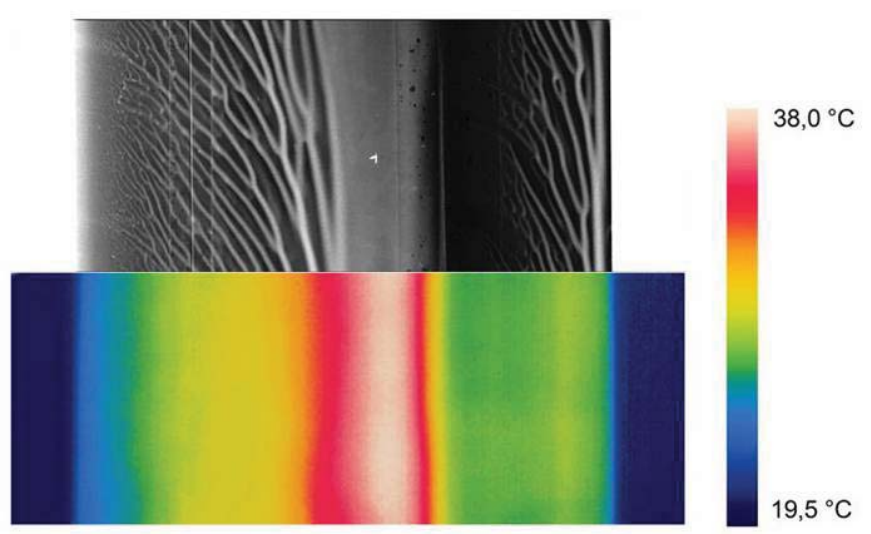

Figure 8: Comparison of wind-tunnel oil flow visualization (top) and infrared camera image (bottom), NACA 63A421 airfoil.
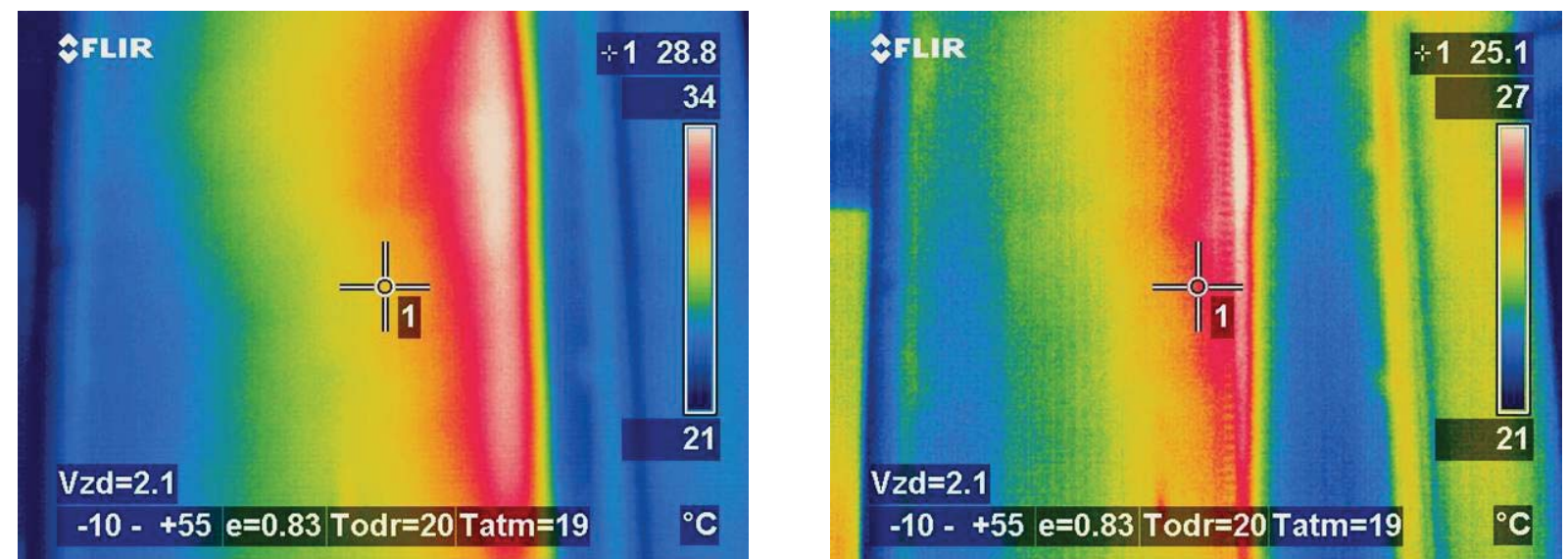

Figure 9: Infrared camera flow visualization, wind-tunnel measurement, $\operatorname{Re}=5 \cdot 10^{5}$, HQ10 airfoil with $17 \%$ flap. Natural transition with separation bubble (left), induced transition by turbulator (right). Marker \#1 is located at $0.5 \mathrm{x} / \mathrm{c}$. Note the temperature field along the aileron hinge. 

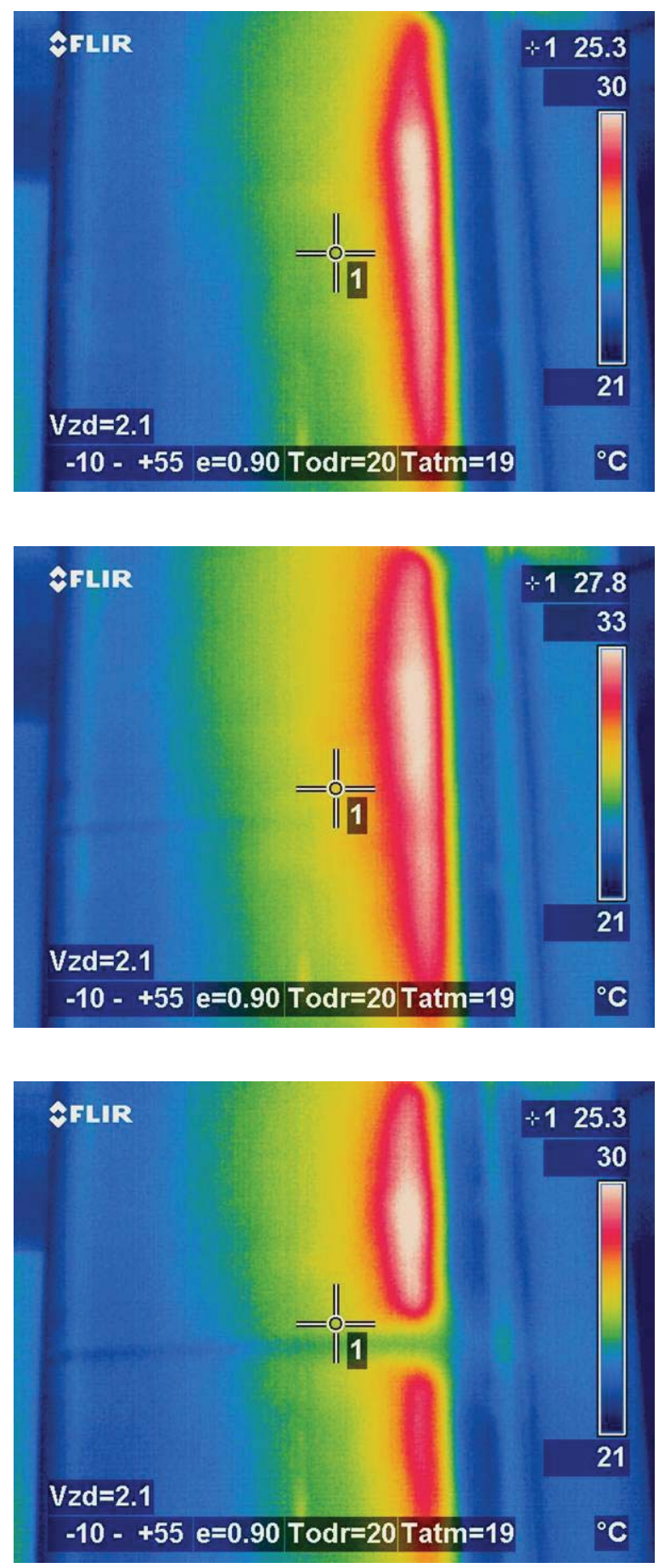

Figure 10: Infrared camera flow visualization, wind-tunnel measurement, Re $=5 \cdot 10^{5}$, HQ10 airfoil, natural transition with separation bubble. Single roughness element, located at $5 \% \times / c$, size $5 \times 5 \mathrm{~mm}$, height $0.3 \mathrm{~mm}, 0.6 \mathrm{~mm}$, $0.9 \mathrm{~mm}$ (from top to bottom). 

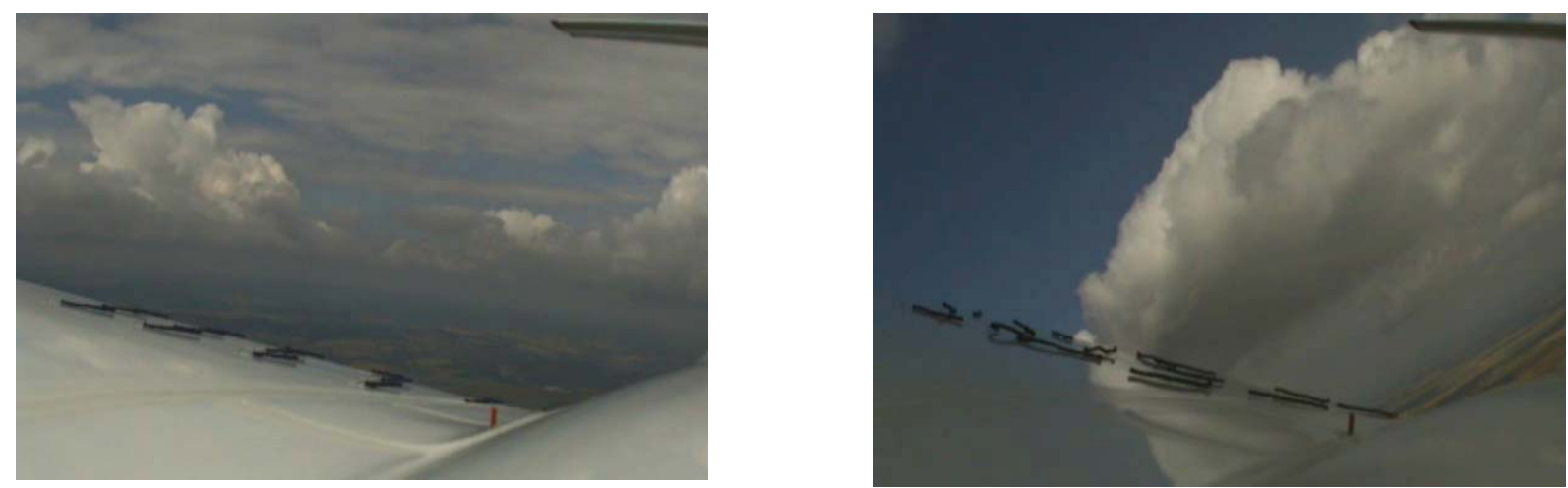

Figure 11: VSO10C sailplane, wing root tuft visualization, $V=140 \mathrm{~km} / \mathrm{h}$ IAS, attached flow (left); V = $70 \mathrm{~km} / \mathrm{h}$ IAS, bank angle 30deg, stalled flow (right).
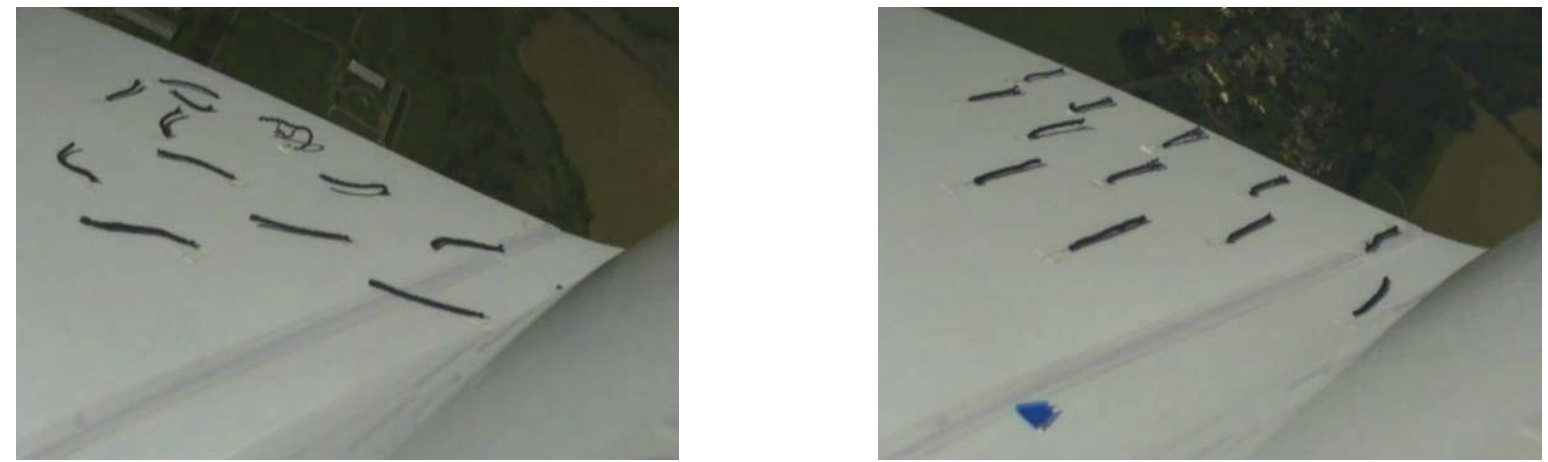

Figure 12: SH Cirrus sailplane, tuft visualization on a wing root in flight, V = $80 \mathrm{~km} / \mathrm{h}$ IAS, uncontrolled (left), with vortex generators (right). 